\title{
Association between Erythropoietin in Cord Blood of Twins and Size at Birth: Does It Relate to Gestational Factors or to Factors during Labor or Delivery?
}

\author{
RUTH MORLEY, VIVIENNE M. MOORE, TERENCE DWYER, JULIE A. OWENS, \\ MARK P. UMSTAD, AND JOHN B. CARLIN
}

\begin{abstract}
Department of Paediatrics, University of Melbourne, and Murdoch Childrens Research Institute, Royal Children's Hospital [R.M., J.B.C.], Parkville, Victoria 3052, Australia; Department of Public Health [V.M.M.], University of Adelaide, Royal Adelaide Hospital, South Australia 5005, Australia; Menzies Research Institute [T.D.], Hobart, Tasmania 7001, Australia; Department of Obstetrics and Gynaecology [J.A.O.], University of Adelaide, Medical School North, South Australia 5005, Australia; and Royal Women's Hospital [M.P.U.], Carlton, Victoria 3053, Australia Abbreviations
\end{abstract}

\begin{abstract}
We hypothesized that cord blood erythropoietin (EPO), a marker of fetal hypoxia, relates to gestational factors and not solely those associated with delivery. We investigated the association between birth weight SD score (SDS) and cord blood EPO in 290 twins (145 pairs), assessing the influence of gestational versus perinatal factors by comparing the association in those who were delivered by elective cesarean (CS) with that in other delivery modes. Blood EPO values were skewed, so geometric means are presented and log EPO values were used in statistical models. The birth size-EPO association was estimated in mixed-effects models that included terms that represented difference in log EPO and mean log EPO for each twin pair. Within-pair estimates of the association were unconfounded by maternal factors (because these were perfectly controlled). Geometric mean EPO was higher in boys versus girls (24.4 versus $17.0 \mathrm{IU} / \mathrm{L} ; p=0.0001)$ and increased with gestational age ( $p=$ 0.0003 ) but was similar after elective CS versus other delivery modes. The negative birth size-EPO association was stronger in
\end{abstract}

\section{ABSTRACT}

infants who were delivered by elective CS than by other delivery modes $\left[\beta\right.$ for $\log _{2}$ EPO: -0.56 (95\% CI, -0.77 to -0.36$)$ versus -0.27 ( -0.42 to -0.12 ), respectively; $p=0.02$ for interaction). Because the association was seen after elective CS delivery, cord blood EPO must relate to factors during gestation, not just perinatal factors. There was no evidence of an association between birth weight SDS and pair mean log EPO, indicating that the association is entirely due to fetus-specific rather than pairspecific factors. (Pediatr Res 57: 680-684, 2005)
CI, confidence interval
CS, cesarean section
DZ, dizygotic
EPO, erythropoietin
MZ, monozygotic
SDS, SD score

\section{Abbreviations} Ablin

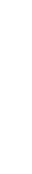

Size at birth (standardized for sex and gestational age) reflects intrauterine growth. This is determined substantially by maternal acquisition of oxygen and nutrients and their transfer to the fetus via the placenta (1). It is difficult to study the contributions of and interactions between maternal and placental factors, especially in large cohorts, but twin pregnancies may offer such an opportunity, because maternal factors are shared, whereas placental factors can be discordant $(2,3)$.

Received May 10, 2004; accepted September 10, 2004

Correspondence: Ruth Morley, FRCPCH University of Melbourne, Department of Paediatrics, Royal Children's Hospital, Flemington Road, Parkville, Victoria 3052 Australia; e-mail: morleyr@unimelb.edu.au.

This study was funded by the Australian National Health and Medical Research Council. R.M. is funded by VicHealth (the Victorian Health Promotion Foundation).

DOI: 10.1203/01.PDR.0000156505.12614.FF
As an indicator of fetal oxygenation (4), cord blood erythropoietin (EPO) reflects adequacy of oxygen delivery to the fetus. It is of fetal origin because maternal EPO does not cross the human placenta (5-7). Raised cord blood EPO indicates fetal hypoxemia and impaired oxygen transfer to the fetus, an impairment that may extend to delivery of other substrates that are essential for fetal growth (8).

A number of studies have demonstrated a relationship between EPO in cord blood and size at birth, including studies of twins $(4,9-12)$. However, there is evidence that EPO level rises within $\sim 4 \mathrm{~h}$ of an episode of hypoxia, (13) and neonates who are small for gestation may be more likely to sustain perinatal asphyxia (14). Thus, the observed negative association between birth weight and cord blood EPO could primarily 
relate to factors during labor and delivery, rather than during gestation.

We investigated the hypothesis that the association was due to factors during gestation and not solely those during labor or delivery, by stratifying analyses according to whether the mother labored. If the association were seen in infants whose mothers had an elective (preplanned) cesarean section (CS), then we could conclude that EPO does relate to factors during gestation. The association between birth weight and cord blood EPO was examined within twin pairs so that we could obtain an estimate that was not confounded by between-pair differences in maternal factors (which would include maternal nutrition, lifestyle, health, and obstetric course) (2).

\section{METHODS}

This study was approved by the Human Research and Ethics Committees of the Royal Women's Hospital and the Mercy Hospital for Women in Melbourne and the Women's and Children's Hospital in Adelaide. Consenting women with twin pregnancies were recruited between 18 and $20 \mathrm{wk}$ of gestation in the Multiple Pregnancy Clinic at the Royal Women's Hospital and in general antenatal clinics at the other two hospitals, as well as in the private consulting rooms of two obstetricians at the Royal Women's Hospital, Melbourne.

Extensive background socioeconomic and obstetric data were recorded as well as nutritional data during pregnancy and information about labor and delivery. The first-born twin and its umbilical cord were identified as twin 1; the second-born twin was identified as twin 2. Cord blood from both twins was collected into both plain and EDTA tubes immediately after delivery and taken to the laboratory for processing and freezing within $1 \mathrm{~h}$ of collection. Placentas that were not clearly separate were sent to the pathology laboratory for determination of chorionicity.

Blood samples from Adelaide were transported on dry ice to Melbourne by air, accompanied by an investigator, and all serum EPO assays were done by RIA (DiaSorin, Stillwater, MN), in accredited laboratories at the Alfred Hospital in Melbourne. Intra-assay coefficient of variation was $5.2 \%$ at 22.9 $\mathrm{mU} / \mathrm{L}$, and interassay coefficient of variation was $6.7 \%$ at $19.0 \mathrm{mU} / \mathrm{L}$. There was $<0.001 \%$ cross-reactivity with other serum proteins, and the lower limit of detection was $4.4 \mathrm{mU} / \mathrm{L}$.

Zygosity of same-sex twins was determined as follows: monochorionic twins were coded as monozygotic (MZ). When infant blood groups had been determined and were different, infants were coded as dizygotic (DZ). For dichorionic twins with unknown or the same blood group, DNA was extracted from cord blood or Guthrie card samples to determine zygosity, on the basis of a standard finger-printing approach using a panel of 12 polymorphic microsatellite markers (D11S4151, D11S904, D12S345, D12S78, D14S283, D17S1852, D2S125, D2S2211, D2S337, D3S1267, D6S257, and D8S284) distributed throughout the genome.

Infant birth weights were taken from routine measurements (all hospitals regularly calibrated their infant scales), and birth weight SD scores (SDS; for gestation and sex) were calculated using British normative data (15).

We included in this study of the association between birth size and EPO only those pairs for whom cord blood samples were collected from both twins. EPO values were skewed, so we report and tabulate geometric mean, and $\log _{2}$ values were used in regression analyses. Analyses were performed using mixed-effects regression models that included a random intercept for each twin pair $(16,17)$. This method was initially used to compare geometric mean values [95\% confidence interval (CI)] of EPO between subgroups (by gestation length, infant sex, mode of delivery, and maternal smoking status), allowing for within-pair correlation. Then we estimated the association between birth weight SDS and EPO within twin pairs by fitting a model with birth weight SDS as dependent variable and including an independent variable representing the difference in log EPO within each twin pair (difference between individual $\log$ EPO and twin pair mean), as well as a term representing pair mean log EPO. This approach allows estimates of associations adjusted for factors shared within twin pairs while also allowing examination of possible independent effects of twin pair-level factors. The resulting estimates of within-pair regression coefficients are identical to those that would be obtained by regressing twin-pair difference values for the outcome on difference values for the covariate (18), and we use this fact to provide a graphical illustration of the strength of association. Logs to base 2 EPO were used so that regression coefficients represented difference in birth weight SDS per doubling of EPO. We tested for effect modification in these models using appropriate interaction terms and report $p$ values from Wald tests. Analyses were performed using Stata (Stata Software Release 8.2; StataCorp, College Station, TX).

\section{RESULTS}

Altogether, 172 women were recruited between July 1999 and January 2003 in Melbourne and 66 between August 2000 and August 2002 in Adelaide; 238 in total. Two hundred (84\%) women remained in the study to delivery. Of the remaining 38 women, 33 withdrew, four miscarried, and one with triplets was recruited in error.

Characteristics of mothers who completed the study to delivery are shown in Table 1. Women who did not remain in the study to delivery differed little from those who did, in terms of mean age, educational level, family size, or obstetric history, but they were more likely to be smoking at the time of recruitment ( 29 versus $12 \%$ respectively; $p=0.02$ by $\chi^{2}$ ).

Cord blood was collected successfully from 303 (76\%) of 400 infants and from both infants of $145(73 \%)$ of 200 pairs. Table 2 shows obstetric data for all 200 women studied to delivery and for mothers of the 145 pairs with blood samples from both. The latter group was reasonably representative.

Of the 145 pairs who both had EPO values, $110(76 \%)$ were DZ dichorionic, 15 (10\%) were MZ dichorionic, and 20 (14\%) were MZ monochorionic pairs. None of the monochorionic pairs had clinical evidence of twin-twin transfusion syndrome. There were 41 male-male pairs, 41 female-female pairs, and 63 mixed-sex pairs.

In Table 3, it can be seen that geometric mean EPO was higher in boys than in girls ( 24.4 versus $17.0 \mathrm{IU} / \mathrm{L}$, respectively; $p=0.0001)$ and increased with gestation length $(p=$ 0.0003 ). Median (interquartile range) gestation did not differ by infant sex; it was $37.1 \mathrm{wk}(35.4-37.9)$ in boys and $37.0 \mathrm{wk}$ (35.4-37.8) in girls. There was little difference in geometric mean EPO between infants who were born by elective CS versus other deliveries.

There was also no strong evidence that maternal smoking or number of cigarettes smoked per day influenced cord blood EPO (see Table 3), although only 18 of the 145 women were smoking at recruitment in the second trimester and 16 in the third trimester.

Relationship between birth weight SDS and EPO. Log EPO was negatively related to birth weight SDS. Adjusting for

Table 1. Characteristics of women who completed the study to delivery

$\begin{array}{lc}\text { Total no. of women } & 200 \\ \text { Mean (SD) maternal age (y) } & 31.9(5.2) \\ \text { Mean (SD) maternal height }(\mathrm{cm}) & 165.5(4.5) \\ \text { Median (interquartile range) maternal } & 69.0(63.0-81.0) \\ \quad \text { weight at recruitment }(18-20 \mathrm{wk} ; \mathrm{kg}) & \\ \text { Median (interquartile range) maternal } & 79.6(72.0-91.0) \\ \quad \text { weight at } \sim 30 \mathrm{wk}(\mathrm{kg}) & \\ N(\%) \text { first pregnancy } & 63(31.5 \%) \\ N(\%) \text { with previous multiple pregnancy } & 5(2.5 \%) \\ N(\%) \text { assisted conception } & 74(38.5 \%) \\ \text { Mother's country of birth }[n(\%)] & \\ \text { Australia or New Zealand } & 151(75.5 \%) \\ \text { Western Europe or North America } & 17(8.5 \%) \\ \text { Other } & 32(16 \%)\end{array}$


Table 2. Obstetric factors and infant characteristics for all infants who were delivered to women in the study and for those with EPO values for both twins

\begin{tabular}{lcc}
\hline & Total & $\begin{array}{c}\text { Infants with EPO } \\
\text { values for both twins }\end{array}$ \\
\hline $\begin{array}{l}\text { No. of infants } \\
\begin{array}{l}\text { Median (interquartile range) gestation } \\
\text { length (wk) }\end{array}\end{array}$ & $\begin{array}{l}\text { 36 (35-38) } \\
N(\%) \text { infants born before } 37\end{array}$ & $37(35-38)$ \\
$\quad \begin{array}{l}\text { completed weeks of gestation } \\
N(\%) \text { infants delivered by elective }\end{array}$ & $1204(51 \%)$ & $140(48 \%)$ \\
$\quad \begin{array}{l}\text { CS } \\
N(\%) \text { infants with monochorionic } \\
\text { placenta }\end{array}$ & $62(15.5 \%)$ & $96(33 \%)$ \\
$N(\%)$ male & $191(48 \%)$ & $145(50 \%)$ \\
\hline
\end{tabular}

Table 3. Geometric mean EPO according to infant sex, mode of delivery, and gestation length

\begin{tabular}{lrcc}
\hline & \multicolumn{3}{c}{ Geometric mean EPO } \\
& $N$ & $(95 \%$ CI $)$ in IU/L & $p$ \\
\hline $\begin{array}{l}\text { All infants } \\
\text { Sex }\end{array} \quad 290$ & $20.4(17.9-23.3)$ & \\
$\quad$ Boys & 145 & $24.4(21.8-28.6)$ & \\
$\quad$ Girls & 145 & $17.0(14.6-29.0)$ & \\
Mode of delivery & & & 0.7 \\
Elective CS & 96 & $19.7(15.6-24.8)$ & \\
Other delivery modes & 194 & $20.8(17.6-24.4)$ & \\
Gestation length & & & 0.0003 \\
$\quad$ 29-35 wk & 64 & $13.3(10.5-17.9)$ & \\
$\quad 35-36$ wk & 76 & $17.8(13.9-22.8)$ & \\
$\quad 37$ wk & 84 & $22.9(18.2-29.0)$ & \\
$\quad 38-41$ wk & 66 & $30.2(23.2-39.3)$ & \\
Maternal smoking in third & & & 0.39 \\
$\quad$ trimester & & & \\
$\quad$ No & 129 & $20.8(18.1-24.0)$ & \\
$\quad$ Yes & 16 & $17.3(11.6-25.8)$ & \\
\hline
\end{tabular}

infant sex and length of gestation, the regression coefficient for $\log _{2}$ EPO (equivalent to difference in birth weight SDS per doubling of EPO) was -0.37 (95\% CI, -0.49 to $-0.24 ; p<$ 0.001 ; Table 4). The strength of this association can be seen in Fig. 1, with twin-pair differences in birth weight SDS plotted against differences in $\log$ EPO (both calculated as twin 1 value - twin 2 value).

This association was substantially stronger in children who were delivered by elective CS versus other modes of delivery ( $p=0.02$ for interaction). The estimated difference in birth weight SDS was -0.56 (95\% CI, -0.77 to -0.36$)$ per dou-

Table 4. Mixed-effects multiple linear regression for birth weight SDS (dependent variable)

\begin{tabular}{llll}
\hline \multicolumn{1}{c}{ Independent variables } & $\beta^{*}$ & \multicolumn{1}{c}{$95 \%$ CI } & $p$ \\
\hline All twins $(n=290)$ & & & \\
$\log _{2}$ EPO within pairs $\dagger$ & -0.37 & -0.49 to -0.24 & $<0.001$ \\
$\log _{2}$ EPO between pairs $\$$ & -0.05 & -0.16 to 0.06 & 0.4 \\
Gestational age (wk) & -0.02 & -0.04 to -0.0003 & 0.048 \\
Infant sex§ & -0.02 & -0.08 to 0.03 & 0.4 \\
\hline
\end{tabular}

* Regression coefficient: estimated difference in birth weight SDS per unit increase in independent variables.

$\dagger$ Coefficient for difference between individual log EPO and twin pair mean.

$\ddagger$ Coefficient for pair mean log EPO.

$\S$ Coded as female versus male.

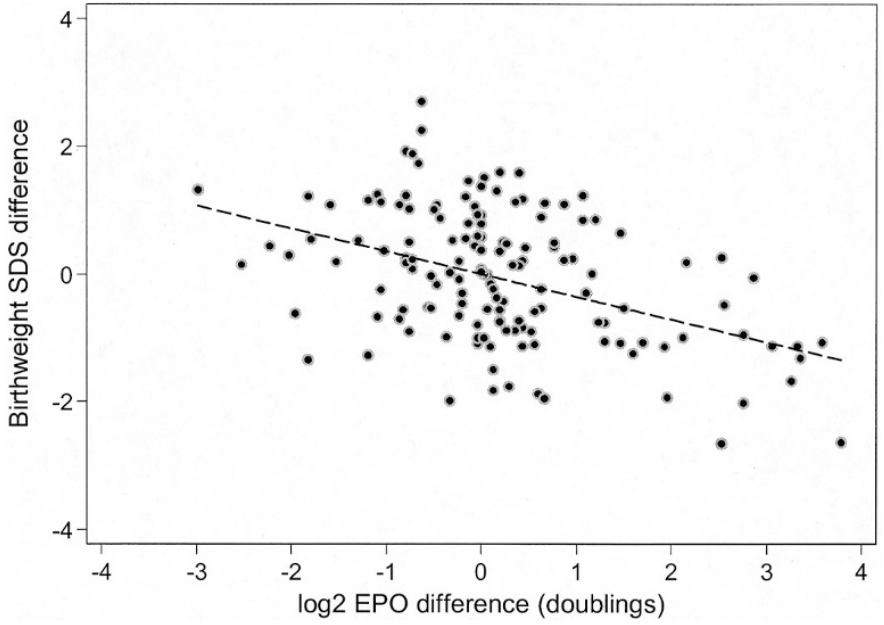

Figure 1. Within-twin pair association of birth weight SDS and $\log _{2}$ EPO. Within-pair difference in log EPO and within-pair difference in birth weight each were calculated as twin 1 value - twin 2 value, where twins were numbered according to birth order (so some difference values are negative and some are positive). As indicated in "Methods," the slope of the least-squares regression line (constrained to fit through the origin) is the same as the within-pair coefficient in the mixed-effects model of Table 4.

bling in EPO in children who were born by elective CS, compared with $-0.27(-0.42$ to -0.12$)$ after other modes of delivery. There was a weak indication that the association was stronger in boys than in girls [difference of $-0.45 \operatorname{SDS}(-0.63$ to -0.28$)$ per doubling in EPO in boys versus $-0.26(-0.46$ to -0.05 ) in girls; $p=0.19$ for interaction].

Regression coefficients were very similar in monochorionic and dichorionic twins ( -0.42 versus -0.36 , respectively), but there were only 20 monochorionic pairs. There was likewise no evidence that the relationship was modified by length of gestation.

In the above models, the regression coefficient representing the independent association between birth weight SDS and twin-pair mean log EPO was very small (e.g. Table 4), indicating that the birth weight SDS-EPO association was entirely due to fetus-specific rather than shared factors.

\section{DISCUSSION}

As expected, we found evidence of a negative association between cord blood EPO and birth weight for gestation and sex (birth weight SDS). This association is consistent with evidence from women who were exposed to lower oxygen tension at high altitude, whose fetuses are relatively growth restricted (19). Our subjects were at lower altitudes, where raised cord blood EPO will indicate fetal hypoxemia that is mainly due to placental or postplacental impairment of the fetal "supply line" for oxygen, and may be accompanied by impaired delivery of other substrates that are essential for fetal growth.

The birth weight SDS-EPO association was seen among infants who were born by elective CS and those who were born by other modes of delivery, and it seemed stronger among those who were born by elective CS ( $p=0.02$ for interaction). We therefore conclude that EPO level in cord blood is an indicator of factors operating during gestation and does not 
solely reflect factors during labor and delivery. Our findings are in agreement with the study of Ostlund et al. (12), who showed that EPO, in amniotic fluid or cordocentesis serum samples from fetuses with signs of growth restriction, correlated negatively with amniotic fluid $\mathrm{Po}_{2}$. It is possible that EPO values in amniotic fluid collected at delivery would provide a more integrated assessment of fetal oxygenation before the onset of labor than cord blood values. This needs to be investigated in other studies.

Infants of women with gestational diabetes tend to be large for gestational age and have higher levels of EPO (20). None of the women in this study had gestational diabetes, so we cannot exclude the possibility that the association between birth weight SDS and EPO is U-shaped.

That the association was stronger in infants who did not experience labor suggests that factors around the time of delivery (e.g. variable length of labor, exposure to acute and intermittent hypoxia) increase variability in EPO levels, "blunting" the underlying association between EPO and fetal growth. This is supported by data showing a greater correlation between prenatal EPO (in amniotic fluid or cordocentesis samples) and cord blood EPO values in infants whose mothers did not labor versus those who experienced labor $(21,22)$. There was no evidence of an independent association between birth weight SDS and pair mean log EPO, confirming that the association was entirely due to fetus-specific rather than shared (including maternal) factors.

DZ twins have two placentas (dichorionic twins), but although MZ twins can also be dichorionic, they often share the same placenta (monochorionic twins). In the latter case, there are always placental vascular communications, so we considered the possibility that EPO might equalize between larger and smaller twins in monochorionic pairs, blunting the association between EPO and size at birth (23). None of the twins in our study had clinical evidence of twin-twin transfusion syndrome. There were too few monochorionic twins to reliably assess whether chorionicity modified the EPO-birth size association, but we found no evidence suggesting that this was the case. Likewise, there was no evidence that the association differed according to gestation length.

Unexpectedly, we found that geometric mean EPO was higher in boys than in girls (24.4 versus $17.0 \mathrm{IU} / \mathrm{L})$. A previous study of 164 samples of amniotic fluid reported no association between EPO and the child's sex (24), as in a study of cord blood from 43 infants (25). However, we found only a weak indication that the association between EPO and birth weight SDS was stronger among boys than among girls $(p=0.19$ for interaction). A study of the relationship between cord blood EPO and cord blood gases demonstrated that in boys, there was a strong negative association between EPO and $\mathrm{PO}_{2}$ and positive association between $\mathrm{EPO}$ and $\mathrm{PCO}_{2}$, but this was not seen in girls (26). These findings suggest that the response of the female fetus to hypoxia, in terms of EPO production, may differ from that of the male fetus. Another possibility is that the male fetus may be exposed to a greater degree of hypoxia in utero. Male fetuses grow faster than female fetuses, with the difference reportedly increasing toward term (27), so they may have increased demand for substrates, including oxygen, com- pared with female fetuses. Sexual dimorphism has been established for hormonal axes that can have an impact on growth and erythropoiesis [e.g. the growth hormone and IGF axis (28) and glucocorticoids (29)], suggesting another potential mechanism. The possibility that the association between EPO and birth size differs according to infant sex and underlying mechanisms needs to be examined in other cohorts of twins and in singletons.

We found strong evidence of a positive relationship between EPO and gestation length. Others have shown that EPO rises with prolonged gestation length in singletons $(30,31)$, and rising EPO may be a marker of increasing placental insufficiency in the third trimester of pregnancy in twins, a period when fetal growth rate diminishes relative to singletons $(32,33)$.

\section{CONCLUSION}

EPO is a marker of the individual twin's oxygenation during gestation and possibly of the sufficiency of their placenta.

Acknowledgments. We thank the women who participated in this study; Maggie Flood, Jodie Bond, Paula Nash, and Priya Duggal for data collection; Jeffrey Robinson for advising us on study design and for help with establishing the study in Adelaide; Margaret Sawyer for undertaking EPO assays; and the large number of midwives, obstetricians, and laboratory staff who generously helped us.

\section{REFERENCES}

1. Harding JE 2001 The nutritional basis of the fetal origins of adult disease. Int $\mathrm{J}$ Epidemiol 30:15-23

2. Morley R, Dwyer T, Carlin JB 2003 Studies of twins: can they shed light on the fetal origins of adult disease hypothesis? Twin Res 6:520-525

3. Redline RW, Shah D, Sakar H, Schluchter M, Salvator A 2001 Placental lesions associated with abnormal growth in twins. Pediatr Dev Pathol 4:473-481

4. Maier RF, Bialobrzeski B, Gross A, Vogel M, Dudenhausen JW, Obladen M 1995 Acute and chronic fetal hypoxia in monochorionic and dichorionic twins. Obstet Gynecol 86:973-977

5. Vora M, Gruslin A 1998 Erythropoietin in obstetrics. Obstet Gynecol Surv 53:500 508

6. Reisenberger K, Egarter C, Kapiotis S, Sternberger B, Gregor H, Husslein P 1997 Transfer of erythropoietin across the placenta perfused in vitro. Obstet Gynecol 89:738-742

7. Widness JA, Schmidt RL, Sawyer ST 1995 Erythropoietin transplacental passagereview of animal studies. J Perinat Med 23:61-70

8. Maier RF, Gunther A, Vogel M, Dudenhausen JW, Obladen M 1994 Umbilical venous erythropoietin and umbilical arterial $\mathrm{pH}$ in relation to morphologic placental abnormalities. Obstet Gynecol 84:81-87

9. Widness JA, Teramo KA, Clemons GK, Coustan DR, Cavalieri RL, Oh W, Welch GP, Schwartz R 1985 Correlation of the interpretation of fetal heart rate records with cord plasma erythropoietin levels. Br J Obstet Gynaecol 92:326-332

10. Lemery DR, Santolaya-Forgas J, Serre AF, Besse GH, Jacquetin B 1995 Fetal serum erythropoietin in twin pregnancies with discordant growth. A clue for the prenatal diagnosis of monochorionic twins with vascular communications. Fetal Diagn Ther 10:86-91

11. Gupta G, Gupta I, Suri V, Dhawan V, Ganguly NK 2000 Estimation of cord blood erythropoietin in pre-eclampsia and eclampsia. Int $\mathrm{J}$ Gynaecol Obstet 71:1-5

12. Ostlund E, Lindholm H, Hemsen A, Fried G 2000 Fetal erythropoietin and endothelin-1: relation to hypoxia and intrauterine growth retardation. Acta Obstet Gynecol Scand 79:276-282

13. Widness JA, Teramo KA, Clemons GK, Garcia JF, Cavalieri RL, Piasecki GJ, Jackson BT, Susa JB, Schwartz R 1986 Temporal response of immunoreactive erythropoietin to acute hypoxemia in fetal sheep. Pediatr Res 20:15-19

14. Tenovuo A Neonatal complications in small-for-gestational age neonates. J Perinat Med 16:197-203, 1988

15. Cole TJ, Freeman JV, Preece MA 1998 British 1990 growth reference centiles for weight, height, body mass index and head circumference fitted by maximum penalized likelihood. Stat Med 17:407-429

16. Verbeke G, Molenberghs G 2000 Linear Mixed Models for Longitudinal Data Springer-Verlag, New York, pp 7-29 
17. Johansson-Kark M, Rasmussen F, De Stavola B, Leon DA 2002 Fetal growth and systolic blood pressure in young adulthood: the Swedish Young Male Twins Study. Paediatr Perinat Epidemiol 16:200-209

18. Young D, Hopper JL, Nowson CA, Green RM, Sherwin AJ, Kaymakci B, Smid M, Guest CS, Larkins RG, Wark JD 1995 Determinants of bone mass in 10- to 26-year-old females: a twin study. J Bone Miner Res 10:558-567

19. Moore LG 2003 Fetal growth restriction and maternal oxygen transport during high altitude pregnancy. High Alt Med Biol 4:141-156

20. Salvesen DR, Brudenell JM, Snijders RJ, Ireland RM, Nicolaides KH 1993 Fetal plasma erythropoietin in pregnancies complicated by maternal diabetes mellitus. Am J Obstet Gynecol 168:88-94

21. Salvesen DR, Brudenell MJ, Nicolaides KH 1995 Effect of delivery on fetal erythropoietin and blood gases in pregnancies with maternal diabetes mellitus. Fetal Diagn Ther 10:141-146

22. Teramo KA, Widness JA, Clemons GK, Voutilainen P, McKinlay S, Schwartz R 1987 Amniotic fluid erythropoietin correlates with umbilical plasma erythropoietin in normal and abnormal pregnancy. Obstet Gynecol 69:710-716

23. Bajoria R, Ward S, Sooranna SR 2001 Erythropoietin in monochorionic twin pregnancies in relation to twin-twin transfusion syndrome. Hum Reprod 16:574-580

24. Buescher U, Hertwig K, Wolf C, Dudenhausen JW 1998 Erythropoietin in amniotic fluid as a marker of chronic fetal hypoxia. Int J Gynaecol Obstet 60:257-263

25. Widness JA, Clemons GK, Garcia JF, Oh W, Schwartz R 1984 Increased immunoreactive erythropoietin in cord serum after labor. Am J Obstet Gynecol 148:194-197
26. Schussler M, Reissenweber J, David E, Reichard K, Hatzmann W 1998 Erythropoietin and obstetric factors-evaluation with special reference to sex differences. Z Geburtshilfe Neonatol 202:64-68

27. Geary MP, Pringle PJ, Rodeck CH, Kingdom JC, Hindmarsh PC 2003 Sexual dimorphism in the growth hormone and insulin-like growth factor axis at birth. J Clin Endocrinol Metab 88:3708-3714

28. Clifton VL, Murphy VE2004 Maternal asthma as a model for examining fetal sex-specific effects on maternal physiology and placental mechanisms that regulate human fetal growth. Placenta 25(suppl A):S45-S52

29. Parker AJ, Davies P, Mayho AM, Newton JR 1984 The ultrasound estimation of sex-related variations of intrauterine growth. Am J Obstet Gynecol 149:665669

30. Manchanda R, Vora M, Gruslin A 1999 Influence of postdatism and meconium on fetal erythropoietin. J Perinatol 19:479-482

31. Jazayeri A, Tsibris JC, Spellacy WN 1998 Elevated umbilical cord plasma erythropoietin levels in prolonged pregnancies. Obstet Gynecol 92:61-63

32. Min SJ, Luke B, Gillespie B, Min L, Newman RB, Mauldin JG, Witter FR, Salman FA, O'Sullivan MJ 2000 Birth weight references for twins. Am J Obstet Gynecol 182:1250-1257

33. Glinianaia SV, Skjaerven R, Magnus P 2000 Birthweight percentiles by gestational age in multiple births. A population-based study of Norwegian twins and triplets. Acta Obstet Gynecol Scand 79:450-458 